\title{
Conserso | Protocolo brasileiro para Infecções Sexualmente Transmissíveis 2020: infecção pelo HIV em adolescentes e adultos
}

doi: 10.1590/S1679-4974202100013.esp1

\author{
Brazilian Protocol for Sexually Transmitted Infections 2020: HIV infection in \\ adolescents and adults
}

Protocolo brasileño para Infecciones de Transmisión Sexual 2020: infección por VIH en adolescentes $y$ adultos

\author{
Lauro Ferreira da Silva Pinto Neto ${ }^{1}$ - (1) orcid.org/0000-0003-2964-8516 \\ Filipe de Barros Perini ${ }^{2}$ - (D) orcid.org/0000-0001-8139-2031 \\ Mayra Gonçalves Aragón ${ }^{3}$ - (1) orcid.org/0000-0001-6631-1790 \\ Marcelo Araújo Freitas ${ }^{3}$ - (1) orcid.org/0000-0002-0763-233X \\ Angélica Espinosa Miranda3 - (1) orcid.org/0000-0002-5556-8379 \\ Escola de Ciências da Saúde da Santa Casa de Misericórdia de Vitória, Vitória, ES, Brasil \\ ${ }^{2}$ Secretaria Municipal de Saúde de Florianópolis, Florianópolis, SC, Brasil \\ ${ }^{3}$ Ministério da Saúde, Secretaria de Vigilância em Saúde, Brasília, DF, Brasil
}

\section{Resumo}

A infecção pelo HIV é tema de um dos capítulos do "Protocolo Clínico e Diretrizes Terapêuticas para Atenção Integral às Pessoas com Infecções Sexualmente Transmissíveis", publicado pelo Ministério da Saúde do Brasil em 2020. É importante que profissionais de saúde e gestores conheçam os sinais e sintomas da infecção pelo HIV e saibam fazer o seu diagnóstico, a fim de oferecer tratamento adequado e reduzir complicações. A infecção pelo HIV tornou-se doença crônica e seu tratamento inclui a abordagem de comorbidades comuns na prática clínica, como hipertensão arterial, diabetes e dislipidemia, além da avaliação de risco cardiológico, prevenção de neoplasias e orientação para imunizações. 0 início do tratamento para todas as pessoas vivendo com HIV, independentemente de critérios clínicos ou imunológicos, adotado pelo Ministério da Saúde em 2013, foi agora simplificado com medicamentos de primeira linha mais toleráveis e com menos interações medicamentosas, o que torna seu manejo de fácil implementação, inclusive pela Atenção Primária à Saúde.

Palavras-chave: Protocolos Clínicos; HIV; Síndrome da Imunodeficiência Adquirida; Tratamento Farmacológico; Comorbidade.

Endereço para correspondência:

Lauro Ferreira Pinto Neto - Rua Chapot Presvot, n 100/1701, Praia do Canto, Vitória, ES, Brasil. CEP: $29057-525$

E-mail: lauro.neto@emescam.br 


\section{Apresentação}

0 presente artigo está relacionado ao capítulo sobre infecção pelo HIV que compõe o "Protocolo Clínico e Diretrizes Terapêuticas para Atenção Integral às Pessoas com Infecções Sexualmente Transmissíveis" (PCDT-IST) e o "Protocolo Clínico e Diretrizes Terapêuticas para Manejo da Infecção pelo HIV em Adultos" (PCDT-HIV), publicados pela Secretaria de Vigilância em Saúde, do Ministério da Saúde do Brasil. Para a elaboração do PCDT, são realizadas a seleção e a análise das evidências disponíveis na literatura e discussão em um painel de especialistas para elaboração das recomendações. Os referidos documentos foram aprovados pela Comissão Nacional de Incorporação de Tecnologias no Sistema Único de Saúde (Conitec) e atualizados pelos grupos de especialistas do PCDT-IST $2020^{1}$ e do PCDT-HIV. ${ }^{2}$

\section{Os casos de HIV estão concentrados em grupos populacionais específicos, como profissionais do sexo, homens que fazem sexo com homens, pessoas transexuais, pessoas que usam álcool e outras drogas e pessoas em situações de vulnerabilidade, como de cor negra, população de rua e privadas de liberdade.}

\section{Aspectos epidemiológicos}

0 vírus da imunodeficiência humana (buman immunodeficiency virus - HIV) é um lentivírus que causa a síndrome da imunodeficiência adquirida (acquired immunodeficiency syndrome - aids), responsável por uma deterioração progressiva do sistema imunológico e que infecta principalmente os linfócitos T (LT) CD4+, os macrófagos e as células dendríticas. ${ }^{3}$ A infecção provoca a diminuição do número de LT-CD4+ por meio de diversos mecanismos, entre os quais a apoptose de células espectadoras, a morte viral de células infectadas e a morte de LT-CD4+ por meio de linfócitos T citotóxicos CD8+ que reconhecem as células infectadas. Quando o número de LT-CD4+ desce abaixo do limiar aceitável, o corpo perde a imunidade mediada por células e torna-se progressivamente mais suscetível a infecções oportunistas. ${ }^{4}$

A infecção pelo HIV pode ser transmitida por sangue, sêmen, lubrificação vaginal ou leite materno. 0 HIV está presente nesses fluidos corporais tanto na forma de partículas livres como em células imunitárias infectadas. ${ }^{5}$ As principais vias de transmissão são as relações sexuais desprotegidas, o compartilhamento de seringas contaminadas e a transmissão entre mãe e filho durante a gravidez ou amamentação. ${ }^{6}$ Pela saliva o risco de transmissão é mínimo.

A epidemia de HIV/Aids no Brasil é considerada estável em nível nacional. A prevalência de HIV na população em geral é de $0,4 \%$. Segundo dados do Ministério da Saúde, em 2018 foram diagnosticados 43.941 novos casos de HIV e 37.161 casos de aids no Brasil, com uma taxa de detecção de 17,8/100.000 habitantes. Desde o ano de 2012 observa-se uma diminuição da taxa de deteç̧ão de aids no Brasil, que passou de 21,4/100.000 habitantes (2012) para 17,8/100.000 habitantes em 2018, configurando um decréscimo de $16,8 \%$. Essa redução da taxa de detecção tem sido mais acentuada desde a recomendação de tratamento para todos os casos, independentemente dos níveis de LT-CD4+, implementada em dezembro de $2013 .{ }^{8}$ Os casos de HIV estão concentrados em grupos populacionais específicos, como profissionais do sexo $(5 \%),{ }^{9}$ homens que fazem sexo com homens $(18 \%),{ }^{10}$ pessoas transexuais $(17 \%-37 \%),{ }^{11}$ pessoas que usam álcool e outras drogas $(5 \%)^{12}$ e aquelas em situações de vulnerabilidade, como pessoas de cor negra, população de rua e pessoas privadas de liberdade. ${ }^{13}$

Estima-se que, ao final de 2018, havia aproximadamente 900 mil pessoas vivendo com HIV (PVHIV) no país, das quais $85 \%$ estavam diagnosticadas; $81 \%$ estavam vinculadas a algum serviço de saúde; e 71\% estavam retidas nos serviços, ou seja, contavam com acompanhamento sistemático de sua condição de saúde em um mesmo serviço de saúde. No mesmo período, a cobertura de terapia antirretroviral (TARV) foi de $66 \%$ e a supressão viral (carga viral inferior a 1.000 cópias $/ \mathrm{mL}$ ) foi de $62 \%$ entre todos os indivíduos infectados pelo HIV. ${ }^{7}$ A profilaxia pré-exposição (PrEP) está disponível desde janeiro de 2018 no Sistema Único de Saúde (SUS), com mais de 11.000 pessoas cadastradas até 2019.7 0 estudo PrEP Brasil, desenvolvido com a finalidade de avaliar a aceitação, a viabilidade e a melhor forma de oferecer a PrEP à população brasileira 
como prevenção ao HIV, mostrou a eficácia e a viabilidade dessa estratégia em um cenário do mundo real. ${ }^{14}$ A oferta de PrEP em clínicas públicas de saúde em um ambiente de renda média pode reter um grande número de participantes e alcançar altos níveis de adesão, sem compensação de risco, nas populações investigadas..$^{15} 0$ uso de profilaxia pós-exposição (PEP) também vem aumentando no país; o número de dispensações de PEP passou de 15.540, em 2009, para 107.345, em 2018.

\section{Aspectos clínicos}

As manifestações clínicas decorrentes da infecção pelo HIV abrangem um grande espectro de sinais e sintomas, com diversas fases, que dependem da resposta imunológica individual e da intensidade de replicação viral. ${ }^{16}$ Frequentemente ocorre um quadro agudo de infecção nas primeiras semanas, seguido de uma fase assintomática, que pode durar anos, antes de surgir a aids. No caso de indivíduos não tratados, o tempo médio entre o contágio pelo HIV e o aparecimento da aids situa-se em torno de dez anos. ${ }^{17,18} \mathrm{~A}$ infecção pelo HIV pode ser classificada em três fases.
Infecção aguda pelo HIV: a infecção aguda pelo HIV assemelha-se à de outras infecções virais. A síndrome retroviral aguda ocorre entre a primeira e a terceira semanas de infecção e caracteriza-se por sintomas inespecíficos como febre, cefaleia, astenia, adenopatia, faringite, exantema e mialgia. A linfadenomegalia acomete principalmente as cadeias cervicais anterior e posterior, submandibular, occipital e axilar. A síndrome retroviral aguda é autolimitada, com resolução espontânea em três a quatro semanas. Diante de um quadro viral agudo, em pessoa sexualmente ativa, 0 médico deve considerar a possibilidade de síndrome retroviral aguda entre os diagnósticos diferenciais. ${ }^{19,20}$

Latência clínica: caracteriza-se por ser em geral assintomática, com duração de anos. É possível encontrar linfadenomegalia e alterações inespecíficas em exames laboratoriais, de pouca importância clínica, como plaquetopenia, anemia (normocrômica e normocítica) e leucopenia. Enquanto a infecção progride, ocorre queda gradual de LT-CD4+, com aparecimento intermitente de infecções, que podem ter apresentações atípicas, ou reativação de infecções antigas, como tuberculose e herpes-zóster. Além disso, podem surgir sinais e sintomas como febre baixa, perda de peso, sudorese noturna e fadiga, além de diarreia, cefalia

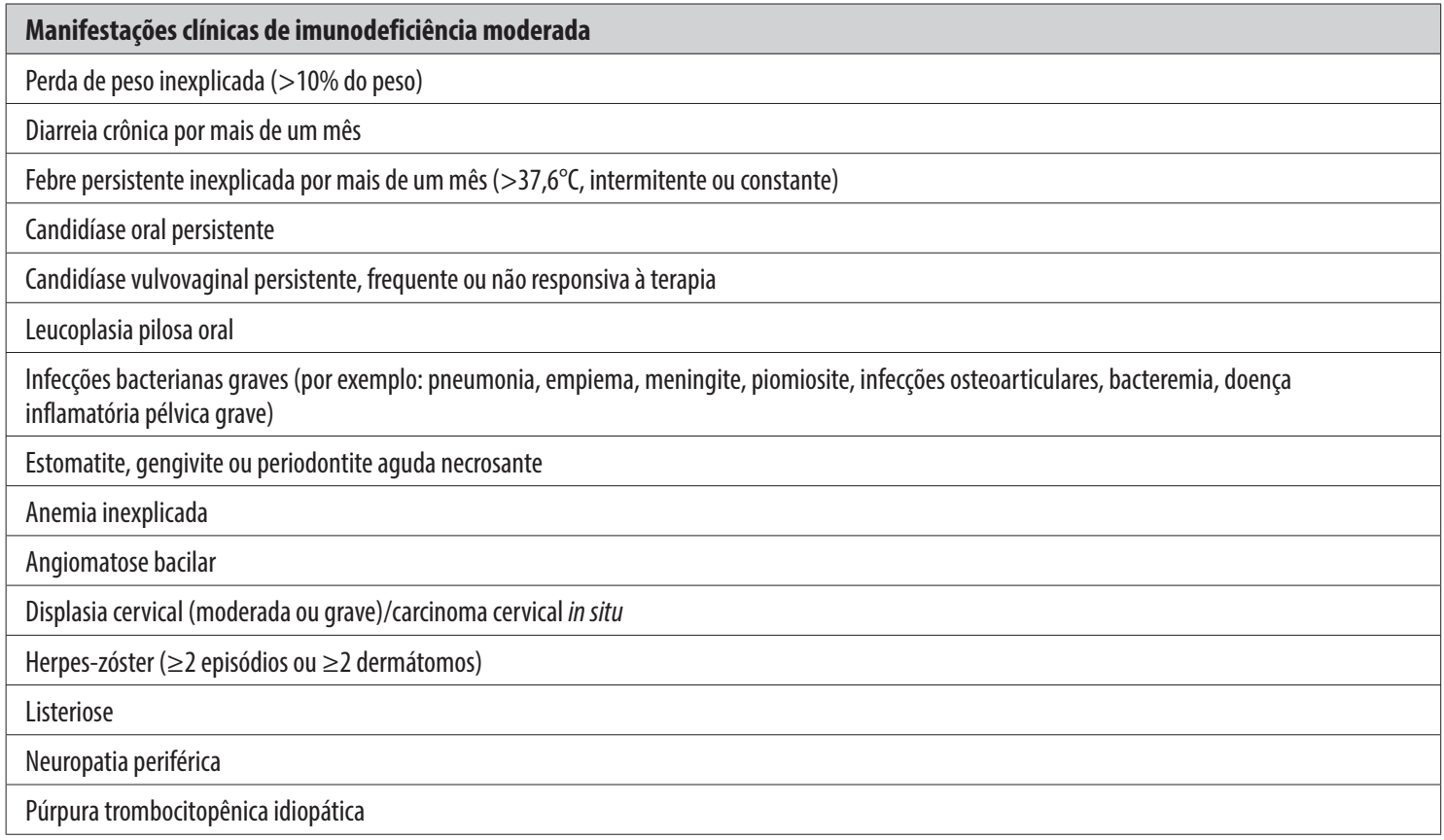

Fonte: adaptado do Protocolo Clínico e Diretrizes Terapêuticas para manejo da infecção pelo HIV em adultos, 2018.22

Figura 1 - Manifestações clínicas de imunodeficiência moderada 


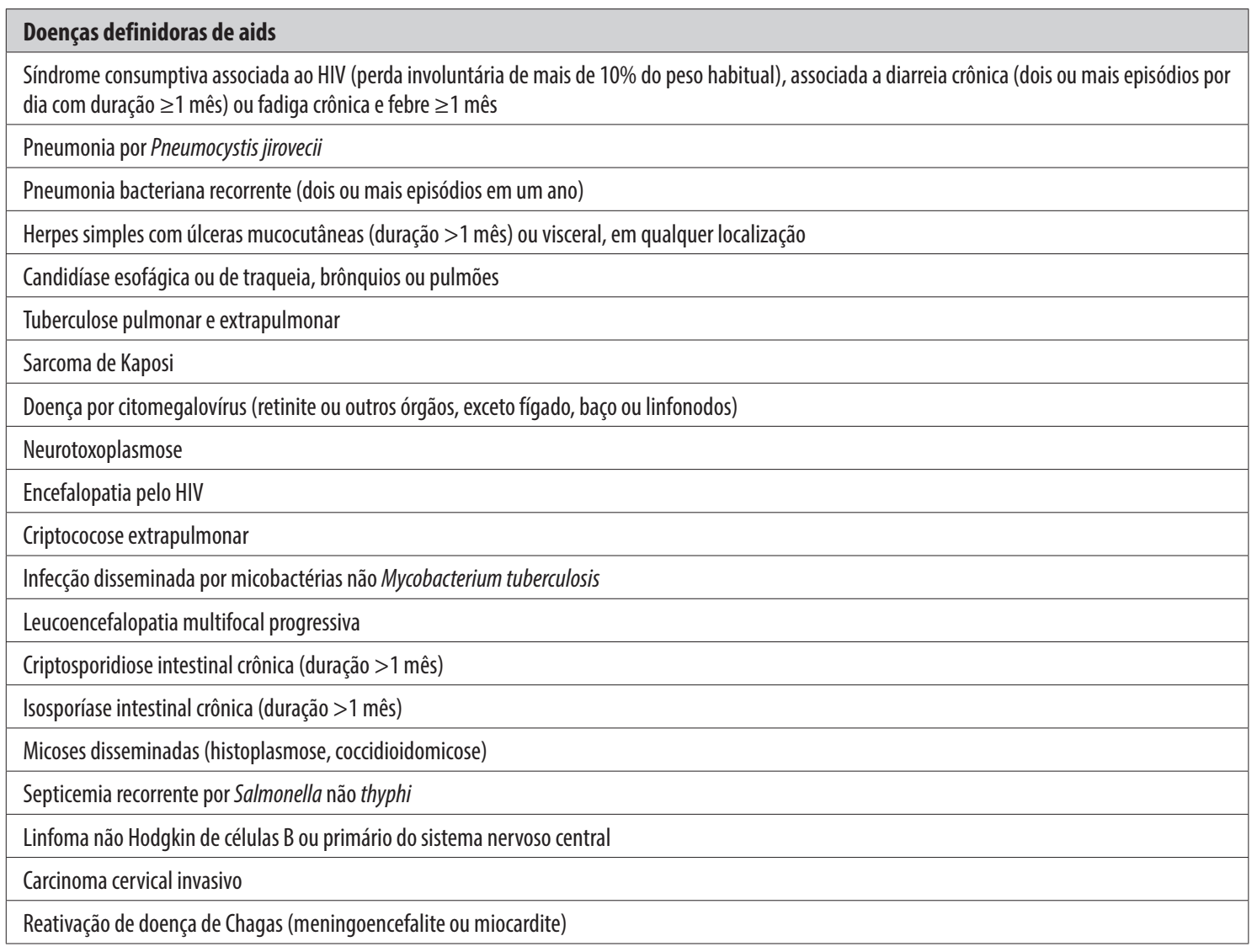

Fonte: adaptado do Protocolo Clínico e Diretrizes Terapêuticas para manejo da infecção pelo HIV em adultos, 2018.22

Figura 2 - Manifestações clínicas de imunodeficiência avançada

e leucoplasia e candidíase orais. As manifestações de imunodeficiência moderada podem surgir nessa fase (Figura 1). ${ }^{21,22}$

Aids: caracteriza-se pelo surgimento de manifestações de imunodeficiência avançada (Figura 2) ${ }^{22} 0$ aparecimento de infecções oportunistas ou neoplasias é indicativo de aids. Dependendo do grau de imunossupressão e especificidades de cada caso, podem ocorrer uma ou várias infecções oportunistas ao mesmo tempo.

\section{Diagnóstico}

0 controle adequado da epidemia de HIV pressupõe ampla e ágil testagem, sem coerção ou discriminação. São especialmente indicadas para testagem as pessoas com alto risco de infecção pelo HIV, incluindo aquelas com sintomas de infecção aguda ou crônica, pessoas com infecções sexualmente transmissíveis (IST), gestantes e pessoas pertencentes a populações vulneráveis, como homens que fazem sexo com homens com status de infecção desconhecido, usuários de drogas e profissionais do sexo. Recomenda-se testar qualquer pessoa sexualmente ativa, em especial aquelas sob risco substancial para infecção pelo HIV. ${ }^{22-24}$

Considera-se caso de infecção pelo HIV aquele que apresenta resultados positivos em dois testes, com metodologias diferentes, ${ }^{25}$ de qualquer uma das quatro combinações descritas na Figura 3. Em quaisquer das combinações de testes, quando a primeira amostra é negativa, a pessoa é considerada não infectada e não há necessidade de testes adicionais. ${ }^{25} 0$ s testes rápidos de terceira geração, amplamente disponíveis no SUS, possuem janela imunológica de 30 dias. $^{25}$

0 diagnóstico de infecção pelo HIV representa um momento ímpar na vida das PVHIV, cujas reações tendem a variar conforme as experiências e conhecimentos prévios de cada indivíduo. Um dos objetivos 


\begin{tabular}{|l|l|l|}
\hline Primeiro teste & Segundo teste & Diagnóstico \\
\hline ELISA quarta geração $(+)$ & Carga viral HIV $\left(P C R^{b}\right)(+)$ & Infecção pelo HIV \\
\hline ELISA terceira geração $(+)$ & Carga viral HIV $(P C R)(+)$ & Infecção pelo HIV \\
\hline ELISA terceira geração $(+)$ & WesternBlot HIV $(+)$ & Infecção pelo HIV \\
\hline $\operatorname{TR}^{c} 1(+)+\operatorname{TR}^{c} 2(+)$ & Carga viral $(\mathrm{PCR})(+)$ & Infecção pelo HIV \\
\hline
\end{tabular}

Fonte: adaptado do Manual Técnico para o Diagnóstico da Infecção pelo HIV, $2018 .{ }^{25}$

Notas: a) ELISA: enzyme-linked immunossorbent assay; b) PCR: polymerase chain reaction; c) TR: testes rápidos 1 e 2 de fabricantes diferentes.

\section{Figura 3 - Testes diagnósticos para detecção da infecção pelo HIV}

primordiais no cuidado é o estabelecimento de uma relação de confiança e respeito entre o profissional de saúde e a PVHIV.

\section{Tratamento}

Os objetivos do tratamento antirretroviral são reduzir a morbidade e mortalidade e prevenir a transmissão do HIV para outras pessoas. ${ }^{26,27}$ Para atingir esses objetivos, o tratamento deve resultar em supressão máxima do HIV. Desse modo, a adesão ao tratamento é condição essencial para o seu sucesso e deve ser discutida desde a primeira consulta. ${ }^{22}$

Abordagem inicial do adolescente e adulto infectado pelo HIV: é necessário estabelecer uma relação de empatia e acolhimento com a pessoa infectada. A anamnese cuidadosa deve detectar situações de risco, antecedentes de IST, doenças crônicas e imunizações. 0 exame físico deve ser completo e incluir exame detalhado da pele e da cavidade oral, aferição da pressão arterial, cálculo do índice de massa corpórea e medida da circunferência abdominal. Exames complementares iniciais e de seguimento clínico estão descritos no "Protocolo Clínico e Diretrizes Terapêuticas para Manejo da Infecção pelo HIV em Adultos" (Figura 4). ${ }^{22}$

Terapia antirretroviral: 0 início imediato da TARV está recomendado para todas as PVHIV, mesmo assintomáticas, independentemente do seu estágio clínico e imunológico. A terapia inicial deve sempre incluir combinações de três antirretrovirais, sendo dois da classe de inibidores da transcriptase reversa análogos de nucleosídeos ou nucleotídeo, associados a um antirretroviral de outra classe. ${ }^{22}$ Essa outra classe pode ser de inibidores da transcriptase reversa não análogos de nucleosídeos, ou inibidores da protease, reforçado com ritonavir ou inibidores de integrase. Em cenário nacional, o esquema preferencial indicado para início de tratamento é a lamivudina + tenofovir + dolutegravir. $^{22}$ Esse esquema envolve 0 uso diário de duas pílulas e é extremamente bem tolerado, com poucos casos de relatos de insônia e cefaleia. ${ }^{28}$ Além de boa tolerância e eficácia, são raros os casos de resistência primária a inibidores da integrase, e poucas interações medicamentosas podem ocorrer. 0s antirretrovirais devem ser utilizados com cautela em pessoas que fazem tratamento com anticonvulsivantes como fenitoína, fenobarbital e carbamazepina e para os casos de coinfecção tuberculose-HIV, em razão da interação com a rifampicina. ${ }^{29,30}$ Além disso, o dolutegravir não deve ser coadministrado com oxicarbamazepina, dofetilida ou pilsicainida, sempre se avaliando a possibilidade de troca dessas medicações a fim de viabilizar o uso do dolutegravir. ${ }^{29}$ Outra exceção é representada por mulheres em idade fértil que pretendam engravidar, em razão do risco potencial de defeito na formação do tubo neural ocasionado pelo dolutegravir nas primeiras 12 semanas de gestação, apesar de esse risco ser muito baixo $(0,19 \%) .{ }^{31}$ Nesse caso, 0 dolutegravir deve ser substituído pelo efavirenz, da classe de inibidores da transcriptase reversa não análogos de nucleosídeos, com genotipagem prévia, em razão do risco de resistência primária. ${ }^{32}$

Falha ao tratamento antirretroviral: a falha virológica é caracterizada pela carga viral do HIV detectável após seis meses do início do tratamento ou troca da terapia, ou carga viral detectável, em indivíduos em tratamento, que eram previamente indetectáveis. Diante da falha virológica, é necessário investigar a possível baixa adesão ao tratamento, bem como a presença de cepas de HIV com mutações de resistência aos antirretrovirais. Nesse caso, o exame de genotipagem é útil para escolha de esquema de resgate com maior eficácia de supressão viral. ${ }^{22}$ 


\begin{tabular}{|c|c|c|c|}
\hline Exame & Pré-TARV & Seguimento & Observação \\
\hline Hemograma completo & Sim & 6-12 meses & Repetir em 2-8 semanas se início ou troca de TARV com AZT'. \\
\hline Creatinina sérica e TFGe & Sim & Anual & $\begin{array}{l}\text { Intervalo de 3-6 meses se uso de TDFd ou outras drogas nefrotóxicas, } \\
\mathrm{TFGe}<60 \mathrm{ml} / \mathrm{min} \text { ou risco aumentado para doença renal (ex.: } \\
\text { diabetes, hipertensão). }\end{array}$ \\
\hline Exame básico de urina & Sim & Anual & $\begin{array}{l}\text { Intervalo de 3-6 meses se uso de TDF ou outras drogas nefrotóxicas, } \\
\text { TFGe }<60 \mathrm{ml} / \mathrm{min} \text {, proteinúria ou risco aumentado para doença renal } \\
\text { (ex.: diabetes, hipertensão). }\end{array}$ \\
\hline $\mathrm{AST}^{\mathrm{e}}, \mathrm{ALT}^{\dagger}, \mathrm{FAg}, \mathrm{BT} \mathrm{T}^{\mathrm{h}}$ e frações & Sim & Anual & $\begin{array}{l}\text { Intervalos mais frequentes em caso de uso de drogas hepatotóxicas, } \\
\text { doença hepática ou coinfecções com HCV' ou HBVj. }\end{array}$ \\
\hline $\mathrm{CT}^{\mathrm{k}}, \mathrm{LDL}^{\prime}, \mathrm{HDL}^{\mathrm{m}}$ e TGL ${ }^{\mathrm{n}}$ & Sim & Anual & Intervalo de 6 meses se alterado na última análise. \\
\hline Glicemia de jejum & Sim & Anual & $\begin{array}{l}\text { Considerar teste de tolerância à glicose caso o resultado da glicemia } \\
\text { de jejum esteja entre } 100 \text { e } 125 \mathrm{mg} / \mathrm{dL} \text {. }\end{array}$ \\
\hline \multirow[t]{2}{*}{$\mathrm{PT} / \mathrm{PPD}^{\circ}$} & \multirow[t]{2}{*}{ Sim } & \multirow{2}{*}{$\begin{array}{l}\text { Anual se LTp-CD4+ } \\
\geq 350 \text { céls/mm³ }\end{array}$} & $\begin{array}{l}\text { Se LT-CD4+<350 céls } / \mathrm{mm}^{3} \text { e excluída tuberculose (TB) ativa, } \\
\text { iniciar tratamento para infecção latente (ILTB) sem necessidade de } \\
\text { realização de PPD. }\end{array}$ \\
\hline & & & $\begin{array}{l}\text { Se tratamento prévio para TB ou ILTB, não há indicação de repetição } \\
\text { - RX de tórax recomendado na consulta pré-TARV. }\end{array}$ \\
\hline Teste imunológico para sífilis & Sim & $\begin{array}{l}\text { Semestral/conforme } \\
\text { indicação }\end{array}$ & Considerar maior frequência de triagem se risco ou exposição. \\
\hline Anti-HCV & Sim & $\begin{array}{l}\text { Anual/conforme } \\
\text { indicação }\end{array}$ & $\begin{array}{l}\text { Considerar maior frequência de triagem se risco ou exposição. } \\
\text { Solicitar carga viral de HCV se anti-HCV positivo ou suspeita de } \\
\text { infecção aguda. }\end{array}$ \\
\hline \multirow{3}{*}{$\begin{array}{l}\text { Triagem HBV (HBsAg }{ }^{q} \text {, antiHBs', } \\
\left.\text { anti-HBc total }{ }^{s}\right)\end{array}$} & \multirow{3}{*}{ Sim } & \multirow{3}{*}{$\begin{array}{l}\text { Anual/conforme } \\
\text { indicação }\end{array}$} & Considerar maior frequência de triagem se risco ou exposição. \\
\hline & & & Vacinar pessoas não imunizadas. \\
\hline & & & $\begin{array}{l}\text { Pessoas imunizadas (anti-HBS positivo) não necessitam nova } \\
\text { triagem para HBV. }\end{array}$ \\
\hline $\begin{array}{l}\text { IgG para toxoplasmose, sorologia para } \\
\text { HTLV1 } 1^{\dagger} \text { e Chagas }\end{array}$ & Sim & - & $\begin{array}{l}\text { Recomendado IgG toxoplasmose em todos. Sorologia para HTLV-1 e } \\
\text { Chagas em áreas endêmicas. }\end{array}$ \\
\hline Rastreamento das alterações ósseas & Não & $2-3$ anos & $\begin{array}{l}>40 \text { anos ou fatores de risco. Avaliar pela "Ferramenta de avaliação } \\
\text { de risco de fratura" - FRAX Brasil.." }\end{array}$ \\
\hline $\begin{array}{l}\text { Avaliação cardiovascular (escala de } \\
\text { risco de Framingham) }\end{array}$ & Sim & Anual & Frequências maiores conforme risco inicial e TARV em uso. \\
\hline Rastreamento de neoplasias & - & - & Abordar no diagnóstico e conforme indicação específica. \\
\hline Imunizações & - & - & Abordar no diagnóstico e conforme indicação específica. \\
\hline Contagem LT-CD4/CD8 & Sim & $6 / 6$ meses & $\begin{array}{l}\text { Com CV-HIV indetectável em } 2 \text { exames e LT-CD4 } \geq 350 \text {, não há } \\
\text { necessidade de monitorar. }\end{array}$ \\
\hline Carga viral HIV & Sim & $\begin{array}{l}\text { 4-8 semanas após início } \\
\text { ou troca e } 6 / 6 \text { meses }\end{array}$ & Repetir se falha virológica. \\
\hline Genotipagem HIV & - & - & $\begin{array}{l}\text { Indicada para gestantes, crianças e adolescentes, casos de HIV-TB, } \\
\text { pessoas infectadas por parceiros em uso de TARV e falha virológica } \\
\text { confirmada. }\end{array}$ \\
\hline
\end{tabular}

Fonte: adaptado do Protocolo Clínico e Diretrizes Terapêuticas para manejo da infecção pelo HIV em adultos, 2018.22

Notas: a) TARV: terapia antirretroviral; b) AZT: zidovudina; c) TFGe: taxa de filtração glomerular estimada; d) TDF: tenofovir; e) AST: aspartatoaminotransferase; f) ALT: alanina aminotransferase; g) FA: fosfatase alcalina; h)BT: bilirrubina total; i) H(V:vírus da hepatite (; j) HBV:vírus da hepatite B; k)(T: colesterol total; I) LDL: low density lipoprotein; m) HDL: high density lipoprotein; n) TGL: triglicerídeos; o) PT/PPD: teste tuberculínico; p) LT: linfócitos T; q) HBsAg: antígeno de superfície da hepatite B; r) Anti-HBs: anticorpos contra antígeno de superfície da hepatite B; s) Anti-HBc total: anticorpos totais contra 0 antígeno do núcleo da hepatite B; t) HTLV: vírus T-linfotrópico humano; u) Acessível pelo link: https://www.sheffield.ac.uk/FRAX/tool.aspx?country=55. Ao usar a calculadora FRAX, deve-se clicar na caixa de causa secundária de osteoporose (campo "10. 0steoporose secundária”).

Figura 4 - Exames complementares iniciais e de seguimento clínico de pessoas com HIV 
Comorbidades em PVHIV em uso de terapia antirretroviral: como a infecção pelo HIV se tornou uma doença crônica, doenças cardiovasculares, hipertensão arterial, diabetes, síndrome metabólica e outras comorbidades se tornaram prevalentes entre as PVHIV. ${ }^{33-35}$ Tabagismo, dislipidemia e alterações renais, hepáticas, osteoarticulares e cognitivas também precisam ser manejadas. ${ }^{33,36,37}$ Assim, deve-se realizar uma abordagem integral essas pessoas, alinhada aos princípios da atenção primária à saúde. ${ }^{22}$

Monitoramento laboratorial da infecção pelo HIV utilizando contagem de LT-CD4+ e carga viral: a contagem de LT-CD4+ é um dos exames de maior importância para avaliar a indicação das imunizações e das profilaxias para infecções oportunistas. ${ }^{22}$ Por meio dele, é possível avaliar o grau de comprometimento do sistema imune, verificar a recuperação da resposta imunológica ao tratamento e definir o momento de interromper as profilaxias. Para casos estáveis, em TARV, com carga viral indetectável e contagem de LT-CD4+ acima de 350 céls $/ \mathrm{mm}^{3}$, a realização do exame de LT-CD4+ não traz benefício ao monitoramento clínico-laboratorial. Flutuações laboratoriais e fisiológicas de LT-CD4+ não têm relevância clínica e podem inclusive levar a erros de conduta, como a troca precoce de esquemas de TARV ou a manutenção de esquemas em falha virológica. ${ }^{38-41}$ A carga viral deve ser 0 foco principal do monitoramento laboratorial nas PVHIV em uso de terapia antirretroviral, o que possibilita a detecção precoce de falha virológica. No Brasil, os profissionais de saúde podem consultar o Sistema Laudo, que disponibiliza informações para o monitoramento clínico das pessoas vivendo com HIV, como o histórico de exames de LT-CD4+ e carga viral, histórico de dispensação de TARV e resultados de genotipagens. ${ }^{42}$

Exames complementares e avaliações de seguimento clínico: além dos exames de contagem de LT-CD4+ e carga viral, outros parâmetros devem ser monitorados nas PVHIV. 0 seguimento clínico com exames complementares é necessário. A frequência de exames realizados depende da condição clínica e do uso de terapia antirretroviral pela PVHIV (Figura 4). ${ }^{22}$ Destaca-se a importância da investigação das IST, tuberculose ativa, risco cardiovascular e rastreamento de neoplasias (em especial o câncer de colo de útero em mulheres cis e homens trans). ${ }^{43}$

0 seguimento clínico deve adequar-se às condições clínicas da PVHIV e à fase do tratamento. 0 primeiro retorno após o início ou alteração da TARV deve ocorrer em torno de sete a 15 dias, com avaliação de eventos adversos e problemas relacionados à adesão medicamentosa. A adaptação ao uso da TARV deve ser avaliada individualmente e podem ser necessários retornos mensais até se alcançar maior adesão. A determinação de um exame de carga viral é recomendada entre quatro e oito semanas de tratamento para avaliar eficácia. Sugere-se a periodicidade mínima de consultas médicas de seis em seis meses para casos de quadros clínicos estáveis em uso de TARV. Nesses casos, exames de controle serão realizados semestralmente, ou conforme avaliação e indicação. Nos intervalos entre as consultas médicas, o reforço à adesão deve ser estimulado nos momentos da dispensação dos medicamentos ou da realização de exames. ${ }^{22}$

Imunizações: todas as vacinas do calendário nacional são recomendadas para adultos e adolescentes vivendo com HIV, desde que estes não apresentem deficiência imunológica importante. Em caso de sintomas ou imunodeficiência grave (LT-CD4+ abaixo de 200 céls $/ \mathrm{mm}^{3}$ ), sugere-se adiar a administração de vacinas, se possível. Vacinas de bactérias ou vírus vivos atenuados não devem ser realizadas naqueles com LT-CD4+ abaixo de 200 céls $/ \mathrm{mm}^{3}$; para aqueles com LT-CD4+ entre 200 e 350 céls $/ \mathrm{mm}^{3}$, os riscos e benefícios dessas vacinas devem ser avaliados (Figura 5). ${ }^{22,44}$

\section{Vigilância, prevenção e controle}

0 uso de linguagem acessível pelos profissionais de saúde é fundamental para a compreensão das PVHIV sobre aspectos relacionados à infecção, transmissibilidade, rotina da avaliação clínico-laboratorial, adesão ao tratamento e enfrentamento ao estigma e à discriminação. ${ }^{22} 0$ diálogo permite 0 esclarecimento de dúvidas e auxilia a superação de dificuldades clínicas, sociais e comportamentais.

Outros aspectos a serem abordados rotineiramente pelo profissional são a saúde sexual da pessoa e suas parcerias, bem como o desejo de reprodução. Orientações objetivas sobre as estratégias atuais de prevenção combinada auxiliam na redução do risco de transmissão do HIV e das IST e permitem que a decisão sobre a concepção seja feita no melhor cenário clínico, com as menores chances de transmissão vertical e sexual. ${ }^{45,46}$

As parcerias sexuais das PVHIV devem ter acesso, de forma ética, a diagnóstico e tratamento oportunos. 


\begin{tabular}{|c|c|}
\hline Vacina & Recomendação \\
\hline \multirow{2}{*}{ Tríplice viral } & Duas doses nos suscetíveis até 29 anos com LTa-CD+ >200 céls/mm³. \\
\hline & Uma dose nos suscetíveis entre 30 e 49 anos com LT-CD+ > 200 céls $/ \mathrm{mm}^{3}$. \\
\hline Varicela $^{\mathrm{b}}$ & Duas doses com intervalo de três meses nos suscetíveis com LT-CD4+ > 200 céls/mm³. \\
\hline Febre amarela ${ }^{b}$ & $\begin{array}{l}\text { Individualizar o risco/benefício conforme a situação imunológica, bem como a situação } \\
\text { epidemiológica da região. Vacinar quando LT-CD4+ > } 200 \text { céls/mm³. }\end{array}$ \\
\hline Dupla do tipo adulto (dT) & Três doses (0, 2, 4 meses) e reforço a cada 10 anos. \\
\hline Haemophilus influenzae tipo b (Hib) & Duas doses com intervalo de dois meses nos menores de 19 anos não vacinados. \\
\hline Hepatite A & $\begin{array}{l}\text { Duas doses com intervalo de } 6 \text { a } 12 \text { meses em indivíduos suscetíveis à hepatite } A \text { (anti-HAV } \\
\text { negativo), portadores de hepatopatia crônica, incluindo portadores crônicos do vírus da hepatite } \\
\text { B eC. }\end{array}$ \\
\hline Hepatite B & $\begin{array}{l}\text { Dose dobrada recomendada pelo fabricante, administrada em quatro doses ( } 0,1,2 \text { e } 6 \text { a } 12 \\
\text { meses) em todos os indivíduos suscetíveis à hepatite } B \text { (anti-HBd }{ }^{d} \text { negativo, anti-HBs negativo). }\end{array}$ \\
\hline Pneumocócica 23-valente & $\begin{array}{l}\text { Se esquema de vacinação iniciado com pneumocócica } 23 \text {-valente: fazer uma dose pneumo-13 } \\
\text { após } 1 \text { ano da pneumo-23. Revacinação com pneumo-23 após } 5 \text { anos da primeira dose } \\
\text { pneumo-23. }\end{array}$ \\
\hline Pneumocócica 13-valente & $\begin{array}{l}\text { Se esquema de vacinação iniciado com pneumocócica 13-valente: após a pneumo 13, fazer uma } \\
\text { dose pneumo-23 após } 8 \text { semanas. Revacinação com pneumo- } 23 \text { após } 5 \text { anos. }\end{array}$ \\
\hline Meningocócica C conjugada & Uma dose e repetir a cada 5 anos. \\
\hline Influenza & Uma dose anual da vacina inativada contra o vírus influenza. \\
\hline $\begin{array}{l}\text { Vacina papilomavírus humano } 6,11,16 \text { e } 18 \\
\text { (recombinante) - HPV quadrivalente }\end{array}$ & $\begin{array}{l}\text { Indivíduo entre } 9 \text { e } 26 \text { anos, desde que tenha a contagem de LT-CD4+ > } 200 \text { céls } / \mathrm{mm}^{3} \text {. } \\
\text { Administrar dose } 1 \text {, agendar dose } 2 \text { com intervalo de dois meses após a dose } 1 \text { e realizar dose } 3 \\
\text { com intervalo de seis meses após a dose } 1 \text { (0, } 2 \text { e } 6 \text { meses). }\end{array}$ \\
\hline
\end{tabular}

Fonte: adaptado do Protocolo Clínico e Diretrizes Terapêuticas para manejo da infecção pelo HIV em adultos, 2018.22

Notas: a) LT: linfócitos T; b) Contraindicada em gestantes; c) Anti-HAV: anticorpos contra hepatite A; d) Anti-HBc: anticorpos contra 0 antígeno do núcleo da hepatite B; e) Anti-HBs: anticorpos contra antígeno de superfície da hepatite $B$.

\section{Figura 5 - Esquema vacinal para maiores de 13 anos infectados pelo HIV}

Para parceiros soronegativos, é importante oferecer estratégias de prevenção combinada, como o uso de preservativos, além de investigar outras IST e avaliar a indicação de profilaxia pré-exposição. ${ }^{47}$

A notificação da infecção pelo HIV segue os mesmos critérios de sigilo definidos na Lei de Acesso à Informação (Lei $\left.{ }^{0} 12.527 / 2011\right){ }^{48}$ 0s profissionais de saúde devem notificar todos os casos de portadores de HIV e de pessoas que vivem com aids, mesmo que tenham sido comunicados anteriormente como infecção pelo HIV. Segundo a Portaria do Ministério da Saúde ${ }^{49}$ que define a Lista Nacional de Notificação Compulsória, publicada em 6 de junho de 2014, pessoas com infecção pelo HIV em acompanhamento clínico-laboratorial e diagnosticadas em data anterior devem ser notificadas à medida que comparecerem à rede de serviços de saúde. Os laboratórios da rede privada deverão informar, periodicamente, todos os casos diagnosticados de infecção pelo HIV à vigilância epidemiológica.

\section{Populações e situações especiais}

Coinfecção tuberculose-HIV: as PVHIV devem ser triadas para tuberculose em todas as consultas. Em casos de imunossupressão grave, é necessário investigar também as formas extrapulmonares e disseminadas da tuberculose. Em casos de terapia antirretroviral ainda não iniciada, com contagem de LT-CD4+ inferior a 50 céls $/ \mathrm{mm}^{3}$, recomenda-se iniciar primeiro 0 tratamento para tuberculose e, em até duas semanas, introduzir a TARV. Nos casos com LT-CD4+ igual ou superior a 50 céls $/ \mathrm{mm}^{3}$, a terapia antirretroviral pode ser iniciada até a oitava semana, próximo ao começo da fase de manutenção do tratamento da TB. ${ }^{50}$

A TARV inicial para pessoas coinfectadas TB-HIV é tenofovir + lamivudina + efavirenz, mediante realização de genotipagem pré-tratamento. Na impossibilidade de sua realização ou resultado não disponível em até duas semanas, deve-se utilizar o dolutegravir no lugar 
do efavirenz. Durante o tratamento da tuberculose e até 15 dias após o seu término, deve-se utilizar o dobro da dose habitual de dolutegravir. Caso a tuberculose ativa seja descartada, deve-se avaliar iniciar o tratamento da infecção latente pelo M. tuberculosis. ${ }^{22}$

Coinfecção sífilis e HIV: o diagnóstico e o tratamento da sífilis em PVHIV devem ser realizados da mesma forma que em pessoas não infectadas pelo HIV. Contudo, em PVHIV, pode ocorrer maior frequência de sobreposição de estágios da sífilis, sintomas mais exuberantes e lesões mais agressivas. ${ }^{51,52}$ É muito importante investigar neurossífilis por meio de punção lombar, na presença de sintomas neurológicos ou oftalmológicos, em casos de sífilis terciária ativa ou após falha do tratamento clínico. Caso a pessoa apresente sinais ou sintomas oculares e neurológicos, deve-se encaminhá-la com urgência para o especialista. ${ }^{51,53}$

Populações com maior urgência para início de terapia antirretroviral: a TARV deve ser iniciada uma vez estabelecido o diagnóstico da infecção pelo HIV, independentemente de critérios clínicos e imunológicos. Muitas pessoas têm evolução fatal sem nunca terem sequer iniciado o tratamento, apesar do acesso universal à terapia no país. ${ }^{54}$ Contudo, há situações que exigem maior urgência para 0 início da TARV, como gestantes, devido ao impacto na transmissão vertical do HIV; pessoas com comorbidades graves, como tuberculose ativa, hepatites B ou C e pessoas com risco cardiovascular elevado; e casos com LT-CD4+ inferior a 350céls $/ \mathrm{mm}^{3}$ e sintomáticos, devido ao importante impacto na morbimortalidade. ${ }^{22}$

\section{Contribuição dos autores}

Pinto Neto LF, Perini FB, Aragon MG, Freitas MA e Miranda AE contribuíram com a concepção, delineamento, redação e revisão crítica do manuscrito. Todos os autores aprovaram a versão final do trabalho e são responsáveis por todos os seus aspectos, incluindo a garantia de sua precisão e integridade.

\section{Agradecimento}

Os autores agradecem aos membros do grupo técnico de especialistas responsáveis pela elaboração do "Protocolo Clínico e Diretrizes Terapêuticas para Manejo da Infecção pelo HIV em Adultos" (PCDT-HIV), em 2018, e do "Protocolo Clínico e Diretrizes Terapêuticas para Atenção Integral às Pessoas com Infecções Sexualmente Transmissíveis" (PCDT-IST), em 2020, a contribuição para a realização deste trabalho.

\section{Referências}

1. Brasil. Ministério da Saúde. Portaria MS/SCTIE n ${ }^{0} 42$, de 5 de outubro de 2018. Torna pública a decisão de aprovar o Protocolo Clínico e Diretrizes Terapêuticas para Atenção Integral às Pessoas com Infecções Sexualmente Transmissíveis (IST), no âmbito do Sistema Único de Saúde - SUS [Internet].Diário Oficial da União, Brasília (DF), 2018 out 8 [citado 2020 set 21]; Seção I: 88. Disponível em: http://bvsms.saude.gov.br/ bvs/saudelegis/sctie/2018/prt0042_08_10_2018.html

2. Brasil. Ministério da Saúde. Portaria MS/SCTIE $n^{0} 50$, de23denovembro de2017. Torna pública a decisão de atualizar o Protocolo Clínico e Diretrizes Terapêuticas para prevenção de transmissão vertical de HIV, sífilis e hepatites virais, no âmbito do Sistema Único de Saúde - SUS [Internet].Diário Oficial da União, Brasília (DF), 2017 nov 27 [citado 2020 set 21]; Seção I: 120. Disponível em: http://bvsms.saude.gov.br/bvs/ saudelegis/sctie/2017/prt0050_27_11_2017.html
3. Dullaers M, Thielemans K. From pathogen to medicine: HIV-1-derived lentiviral vectors as vehicles for dendritic cell based cancer immunotherapy. J Gene Med [Internet]. 2006 Jan [cited 2020 Sep 21]; 8(1):317. Available from: https://doi.org/10.1002/jgm.846

4. Fackler 0T, Alcover A, Schwartz 0. Modulation of the immunological synapse: a key to HIV-1 pathogenesis? Nat Rev Immunol [Internet]. 2007 Apr [cited 2020 Sep 21]; 7(4):310-7. Available from: https://doi.org/10.1038/nri2041

5. Shaw GM, Hunter E. HIV transmission. Cold Spring Harb Perspect Med [Internet]. 2012 Nov [cited 2020 Sep 21]; 2(11):a006965. Available from: https://doi.org/10.1101/cshperspect.a006965

6. Simon V, Ho DD, Abdool-Karim Q. HIV/AIDS epidemiology, pathogenesis, prevention, and treatment. Lancet [Internet]. 2006Aug [cited 2020 Sep 21]; 
368(9534):489-504. Available from: https://www. ncbi.nlm.nih.gov/pmc/about/public-access/

7. Ministério da Saúde (BR). Secretaria de Vigilância em Saúde. Departamento de Condições Crônicas e Infecções Sexualmente Transmissíveis. Relatório de monitoramento clínico do HIV [Internet]. Brasília: Ministério da Saúde; 2019 [citado 2020 jul9]. Disponível em: http://www.aids.gov.br/pt-br/pub/2019/ relatorio-de-monitoramento-clinico-do-hiv-2019

8. Ministério da Saúde (BR). Secretaria de Vigilância em Saúde. Departamento de Condições Crônicas e Infecções Sexualmente Transmissíveis. HIV/Aids 2019. BolEpidemiol [Internet].2019 nov [citado 2020 jul 9]; especial. Disponível em: http://www.aids.gov.br/pt-br/ pub/2019/boletim-epidemiologico-de-hivaids-2019

9. Ferreira-Júnior ODC, Guimarães MDC, Damacena GN, Almeida WDS, Souza-Júnior PRB, Szwarcwald CL, Brazilian FSW Group. Prevalence estimates of HIV, syphilis, hepatitis B and C among female sex workers (FSW) in Brazil, 2016. Medicine (Baltimore) [Internet]. 2018 May [cited 2020 Sep 21]; 97(1 Suppl):S3-8. Available from: https:// dx.doi.org/10.1097\%2FMD.0000000000009218

10. Kerr L, Kendall C, Guimarães MDC, Salani Mota R, Veras MA, Dourado I, et al. HIV prevalence among men who have sex with men in Brazil: results of the 2nd national survey using respondent-driven sampling. Medicine (Baltimore) [Internet].2018 May [cited 2020 Sep 21]; 97(1S Suppl 1):S9-15. Available from: https://doi.org/10.1097/md.0000000000010573

11. Bastos FI, Bastos LS, Coutinho C, Toledo L, Mota JC, Velasco-de-Castro CA, et al. HIV, HCV, HBV, and syphilis among transgender women from Brazil: assessing different methods to adjust infection rates of a hard-to-reach, sparse population. Medicine (Baltimore) [Internet]. 2018 May [cited 2020 Sep 21]; 97(1S Suppl 1):S16-24. Available from: https://doi.org/10.1097/md.0000000000009447

12. Bastos FI, Bertone N. Pesquisa nacional sobre o uso de crack: quem são os usuários de crack e/ou similares do Brasil? Quantos são nas capitais brasileiras? [Internet]. Rio de Janeiro: ICICT; Fiocruz; 2014 [citado 2020 set 21]. 224 p. Disponível em: https://www.icict. fiocruz.br/sites/www.icict.fiocruz.br/files/Pesquisa\%20 Nacional\%20sobre\%20o\%20Uso\%20de\%20Crack.pdf

13. Pascom ARP, Meireles MV, Benzaken AS. Sociodemographic determinants of attrition in the HIV continuum of care in Brazil in 2016. Medicine (Baltimore) [Internet]. 2018 May [cited 2020 Sep
21]; 97(1 Suppl):S69-74. Available from: https:// dx.doi.org/10.1097\%2FMD.0000000000009857

14. PrEP Brasil Profilaxia Pré Exposição. Estudo PrEP Brasil [internet]. Rio de Janeiro: Fiocruz; 2020 [citado 2020 jul 29]. Disponível em: https:// prepbrasil.com.br/pesquisa-prep-brasil/

15. Grinsztejn B, Hoagland B, Moreira RI, Kallas EG, Madruga JV, Goulart S, et al. Retention, engagement, and adherence to pre-exposure prophylaxis for men who have sex with men and transgender women in PrEPBrasil: 48 week results of a demonstration study. Lancet HIV [Internet]. 2018 Mar [cited 2020 Sep 21]; 5(3):e136-45. Available from: https://doi.org/10.1016/s2352-3018(18)30008-0

16. Pantaleo G, Graziosi C, Fauci AS. New concepts in the immunopathogenesis of humanimmuno deficiency virus infection. N Engl J Med [Internet]. 1993 Feb [cited 2020 Sep 21]; 328(5):327-35. Available from: https:/open.spotify.com/track/4CaG7bI5Qr1ZjXxsUIBBmA?si=jx-6PkQrTmGmatQ3R3Ct9w

17. Bacchetti P, Moss AR. Incubation period of AIDS in San Francisco. Nature [Internet]. 1989 Mar [cited 2020 Sep 21]; 338(6212):251-3. Available from: https://doi.org/10.1038/338251a0

18. Pedersen C, Lindhardt B0, Jensen BL, Lauritzen E, Gerstoft J, Dickmeiss E, et al. Clinical course of primary HIV infection: consequences for subsequent course of infection. BMJ [Internet]. 1989 Jul [cited 2020 Sep 21]; 299(6691):154-7. Available from: https://dx.doi.org/10.1136\%2Fbmj.299.6692.154

19. Cohen MS, Shaw GM, McMichael AJ, Haynes BF. Acute HIV-1 infection. N Eng J Med [Internet]. 2011 May [cited 2020 Sep 21]; 364(20):1943-54. Available from: https://doi.org/10.1056/nejmra1011874

20. Bottone PD, Bartlett AH. Diagnosing acute HIV infection. Pediatr Ann [Internet]. 2017Feb [cited 2020 Sep 21]; 46(2):e47-50.Availablefrom: https:// doi.org/10.3928/19382359-20170118-01

21. Daar ES, Little S, Pitt J, Santangelo J, Ho P, Harawa $\mathrm{N}$, et al. Diagnosis of primary HIV-1 infection. Los Angeles County Primary HIV Infection Recruitment Network. Ann Intern Med [Internet]. 2001 Jan [cited 2020 Sep 21]; 134(1):25-9. Available from: https:// doi.org/10.7326/0003-4819-134-1-200101020-00010

22. Ministério da Saúde (BR). Secretaria de Vigilância em Saúde. Departamento de Vigilância, Prevenção e Controle das Infecções Sexualmente Transmissíveis, do HIV/Aids e das Hepatites Virais. 
Protocolo clínico e diretrizes terapêuticas para manejo da infecção pelo HIV em adultos [Internet]. Brasília: Ministério da Saúde; 2018 [citado 2020 jul 9]. 412 p. Disponível em: http://www.aids.gov.br/system/ tdf/pub/2016/64484/pcdt_adulto_12_2018_web. pdf?file $=1 \&$ type $=$ node $\&$ id $=64484 \&$ force $=1$

23. Chou R, Dana T, Grusing S, Bougatsos C. Screening for HIV infection in asymptomatic, nonpregnant adolescents and adults: updated evidence reportan dsystematic review for the US preventive services task force. JAMA [Internet]. 2019 Jun [cited 2020 Sep 21]; 321(23):2337-48. Available from: https://doi.org/10.1001/jama.2019.2592

24. Bert F, Gualano MR, Biancone P, Brescia V, Camussi E, Martorana M, et al. Cost-effectiveness of HIV screening in high-income countries: a systematic review. Health Policy [Internet]. 2018 May [cited 2020 Sep 21]; 122(5):533-47. Available from: https://doi.org/10.1016/j.healthpol.2018.03.007

25. Ministério da Saúde (BR). Secretaria de Vigilância em Saúde. Departamento de Vigilância, Prevenção e Controle das Doenças Sexualmente Transmissíveis, Aids e Hepatites Virais. Manual técnico para o diagnóstico da infecção pelo HIV [Internet]. Brasília: Ministério da Saúde; 2018 [citado 2020 jul9]. Disponível em: http://www.aids.gov.br/system/tdf/ pub/2016/57787/manual_tecnico_hiv_27_11_2018_ web.pdf?file $=1 \&$ type $=$ node $\& i d=57787 \&$ force $=1$

26. Cohen MS, Chen YQ, McCauley M, Gamble T, Housseinipour MC, Kumarasamy N,et al. Antiretroviral therapy for the prevention of HIV-1 transmission. $\mathrm{N}$ Engl J Med [Internet]. 2016 Sep [cited 2020 Sep 21]; 375(9):830-9. Available from: https://doi.org/10.1056/nejmoa1600693

27. Le Messurier J, Traversy G, Varsaneux 0, Weekes M, Avey MT, Niragira 0, et al. Risk of sexual transmission of human immunodeficiency virus with antiretroviral therapy, suppressed viral load and condom use: a systematic review. CMAJ [Internet]. 2018 Nov [cited 2020 Sep 21]; 190(46):E1350-60. Available from: https://doi.org/10.1503/cmaj.180311

28. Peñafiel J, Lazzari E, Padilla M, Rojas J, Gonzalez-Cordon A, Blanco JL, et al. Tolerability of integrase inhibitors in a real-life setting. J Antimicrob Chemother [Internet]. 2017 Jun [cited 2020 Sep 21]; 72(6):1752-9. Available from: https://doi.org/10.1093/jac/dkx053

29. Ministério da Saúde (BR). Secretaria de Vigilância em Saúde. Departamento de Condições Crônicas e Infecções Sexualmente Transmissíveis. Ofício circular no 03/2020/CGAHV/DCCI/SVS/MS [Internet].
Brasília: Ministério da Saúde; 2020 [citado 2020 jul 9]. Disponível em: http://www.aids.gov.br/pt-br/ legislacao/oficio-circular-no-32020cgahvdccisvsms

30. Ministério da Saúde (BR). Secretaria de Vigilância em Saúde. Departamento de Condições Crônicas e Infecções Sexualmente Transmissíveis. Ofício circular no 02/2020/CGAHV/DCCI/SVS/MS [Internet]. Brasília: Ministério da Saúde; 2020 [citado 2020 jul 9]. Disponível em: http://www.aids.gov.br/pt-br/ legislacao/oficio-circular-no-22020cgahvdccisvsms

31. Zash R, Holmes L, Diseko M, Jacobson DL, Brummel S, Mayondi B, et al. Neural-tube defects and antiretroviral treatment regimens in Botswana. N Engl J Med [Internet]. 2019 Aug [cited 2020 Sep 21]; 381(9):827-40. Available from: https://doi.org/10.1056/nejmoa1905230

32. Ministério da Saúde (BR). Secretaria de Vigilância em Saúde. Departamento de Condições Crônicas e Infecções Sexualmente Transmissíveis. Ofício Circular no 2/2019/DCCI/SVS/MS [Internet]. Brasília: Ministério da Saúde; 2019 [citado 2020 jul 9]. Disponível em: http://www.aids.gov. br/pt-br/legislacao/oficio-circular-no-22019

33. Wing EJ. HIV and aging. Int J Infect Dis [Internet]. 2016Dec [cited 2020 Sep 21]; 53:61-8. Available from: https://doi.org/10.1016/j.ijid.2016.10.004

34. Ghosn J, Taiwo B, Seedat S, Autran B, Katlama C. HIV. Lancet [Internet].2018Aug [cited 2020 Sep 21]; 392(10148):685-97. Available from: https:// doi.org/10.1016/S0140-6736(18)31311-4

35. Pinto Neto LF, Neves MB, Ribeiro-Rodrigues R, Page $\mathrm{K}$, Miranda AE. Dyslipidemia and fasting glucose impairment among HIV patients three years after the first antiretroviral regimen in a Brazilian AIDS outpatient clinic. Braz J Infect Dis [Internet]. 2013 Jul-Aug [cited 2020 Sep 21]; 17(4):438-43. Available from: https://doi.org/10.1016/j.bjid.2012.12.006

36. Pinto Neto LF, Ragi-Eis S, Vieira NF, Soprani M, Neves MB, Ribeiro-Rodrigues R, et al. Low bone mass prevalence, therapy type, and clinical risk factors in an HIV-infected Brazilian population. J Clin Densitom [Internet]. 20110ct-Dec [cited 2020 Sep 21]; 14(4):434-49. Available from: https://doi.org/10.1016/j.jocd.2011.06.004

37. Pinto Neto LF, Milanez MC, Golub JE, Miranda AE. Malignancies in HIV/AIDS patients attending an outpatient clinic in Vitória, State of Espírito Santo, Brazil. Rev Soc Bras Med Trop [Internet]. 2012Nov-Dec [cited 2020 Sep21]; 45(6):687-90. Available from: https://doi.org/10.1590/S0037-86822012000600006 
38. Deeks SG, Barbour JD, Martin JN, Swanson MS, Grant RM. Sustained CD4+ T cell response after virologic failure of protease inhibitor-based regimens in patients with human immunodeficiency virus infection. J Infect Dis [Internet]. 2000 Mar [cited 2020 Sep 21]; 181(3):946-53. Available from: https://doi.org/10.1086/315334

39. Maggiolo F, Leone S. CD4+ T lymphocyte recovery in individuals with type 1 human immunodeficiency virus infection. Clin Infect Dis [Internet]. 2010 Aug [cited 2020 Sep 21]; 51(4):465-7. Available from: https://doi.org/10.1086/655152

40. Sigaloff KC, Hamers RL, Wallis CL, Kityo C, Siwale $\mathrm{M}$, Ive $\mathrm{P}$, et al. Unnecessary antiretroviral treatment switches and accumulation of HIV resistance mutations; two arguments for viral load monitoring in Africa. J Acquir Immune Defic Syndr [Internet]. 2011 Sep [cited 2020 Sep 21]; 58(1):23-31. Available from: https://doi.org/10.1097/qai.0b013e318227fc34

41. Rawizza HE, Chaplin B, Meloni ST, Eisen G, Rao T, Sankalé JL, et al. Immunologic criteria are poor predictors of virologic outcome: implications for HIV treatment monitoring in resource- limited settings. Clin Infect Dis [Internet]. 2011 Dec [cited 2020 Sep 21]; 53(12):1283-90. Available from: https://doi.org/10.1093/cid/cir729

42. Ministério da Saúde (BR). Secretaria de Vigilância em Saúde. Departamento de Vigilância, Prevenção e Controle das IST, do HIV/Aids e das Hepatites Virais. Sistema laudo [Internet]. Brasília: Ministério da Saúde; 2018 [citado 2020 jul 29]. Disponível em: https://laudo.aids.gov.br/login

43. Casper C, Crane H, Menon M, Money D. HIV/AIDS comorbidities: impact on cancer, noncommunicable diseases, and reproductive health. In: Holmes KK, Bertozzi S, Bloom BR, Jha P, editors. Major infectious diseases. 3rd ed. Washington, DC.: The International Bank for Reconstruction and Development/The World Bank; 2017 [cited 2020 Sep 21]. Available from: https:/www.ncbi.nlm.nih.gov/books/NBK525192/

44. Ministério da Saúde (BR). Secretaria de Vigilância em Saúde. Nota Informativa n ${ }^{0} 384 / 2016$ : mudanças no calendário nacional de vacinação para 0 ano de 2017 [Internet]. Brasília: Ministério da Saúde; 2017 [citado 2020 jul 29]. Disponível em: http://portalsaude.saude. gov.br/images/pdf/2016/dezembro/28/Nota-Informativa-384-Calendario-Nacional-de-Vacinacao-2017.pdf

45. Tudor Car L, van-Velthoven MH, Brusamento S, Elmoniry H, Car J, Majeed A, et al. Integrating prevention of mother-to-child HIV transmission (PMTCT) programs with other health services for preventing HIV infection and improving HIV outcomes in developing countries. Cochrane Database Syst Rev[Internet]. 2011 Jun [cited 2020 Sep 21]; 7(6):CD008741. Available from: https://doi.org/10.1002/14651858.cd008741.pub2

46. Drake AL, Wagner A, Richardson B, John-Stewart G. Incident HIV during pregnancy and postpartum and risk of mother-to-child HIV transmission: a systematic review and meta-analysis. PLoS Med [Internet]. 2014 Feb [cited 2020 Sep 21]; 11(2):e1001608. Available from: https://dx.doi.org/10.1371\%2Fjournal.pmed.1001608

47. Ministério da Saúde (BR). Secretaria de Vigilância em Saúde. Departamento de Vigilância, Prevenção e Controle das Infecções Sexualmente Transmissíveis, do HIV/Aids e das Hepatites Virais. Protocolo clínico e diretrizes terapêuticas para profilaxia pré-exposição (PrEP) de risco à infecção pelo HIV [Internet]. Brasília: Ministério da Saúde; 2018[citado 2020 jul 8]. Disponível em:http://www.aids.gov.br/system/tdf/ pub/2016/64510/miolo_pcdt_prep_11_2018_web. pdf?file $=1 \&$ type $=$ node $\& i d=64510 \&$ force $=1$

48. Brasil. Presidência da República. Casa Civil. Lei $\mathrm{n}^{0} 12.527$, de 18 de novembro de 2011. Regula 0 acesso a informações previsto no inciso XXXIII do art. $5^{\circ}$, no inciso II do $\S 3^{\circ}$ do art. 37 e no $\S 2^{\circ}$ do art. 216 da Constituição Federal; altera a Lei $n^{0}$ 8.112, de 11 de dezembro de 1990; revoga a Lei $\mathrm{n}^{0} 11.111$, de 5 de maio de 2005, e dispositivos da Lei $n^{\circ} 8.159$, de 8 de janeiro de 1991; e dá outras providências [Internet]. Diário Oficial da União, Brasília (DF), 2011 nov 18 [citado 2020 jul]; Seção I: extra. Disponível em: http:/www.planalto.gov.br/ ccivil_03/_ato2011-2014/2011/lei/112527.htm

49. Brasil. Ministério da Saúde. Secretaria de Vigilância em Saúde. Portaria MS/GMn ${ }^{0} 1.271$, de 6 junho de 2014. Define a Lista Nacional de Notificação Compulsória de doenças, agravos e eventos de saúde pública nos serviços de saúde públicos e privados em todo 0 território nacional, nos termos do anexo, e dá outras providências [Internet].Diário Oficial da União, Brasília (DF), 2014 jun 9 [citado 2020 jul 9]; Seção I:67. Disponível em: http://bvsms.saude.gov.br/bvs/ saudelegis/gm/2014/prt1271_06_06_2014.html

50. World Health Organization - WHO. Guidelines for treatment of drug-susceptible tuberculosis and patient care, 2017 update [Internet]. Genebra: World Health Organization; 2017 [cited 2020 Jul 9]. 56 p. Available from: http://apps.who.int/iris/bitstream/10665/255052/1/9789241550000-eng.pdf?ua=1 
51. Clement ME, Okeke NL, Hicks CB. Treatment of syphilis: a systematic review. JAMA [Internet]. 2014 Nov [cited 2020 Sep 21]; 312(18):1905-17. Available from: https://doi.org/10.1001/jama.2014.13259

52. Peeling RW, Mabey D, Kamb ML, Chen XS, Radolf JD, Benzaken AS. Syphilis. Nat Rev Dis Primers [Internet]. 2017 0ct [cited 2020 Sep 21]; 3:17073. Available from: https://doi.org/10.1038/nrdp.2017.73

53. Ministério da Saúde (BR). Secretaria de Vigilância em Saúde. Departamento de Doenças de Condições Crônicas e Infecções Sexualmente Transmissíveis. Protocolo clínico e diretrizes terapêuticas para atenção integral às pessoas com infecções sexualmente transmissíveis (IST) [Internet]. Brasília: Ministério da Saúde; 2020 [citado 2020 jul 9]. 248 p. Disponível em: http://www.aids.gov.br/system/tdf/ pub/2016/57800/pcdt_ist_final_revisado_020420. pdf?file $=1 \&$ type $=$ node $\&$ id $=57800 \&$ force $=1$

54. Freitas MA, Miranda AE, Pascom ARP, Oliveira SB, Mesquita F, Ford N. Antiretroviral therapy status among people who died of AIDS-related causes from 2009 to 2013 in Brazil: a population-based study. Trop MedInt Health [Internet]. 2016 Nov [cited 2020 Sep 21]; 21(11):1452-7. Available from: https://doi.org/10.1111/tmi.12778

\section{Abstract}

HIV infection is the subject of one of the chapters of the "Clinical Protocol and Therapeutic Guidelines for Comprehensive Care for People with Sexually Transmitted Infections", published by the Brazilian Ministry of Health in 2020. It is important that bealth professionals and managers learn the signs and symptoms of HIV infection and know how to diagnose it, in order to provide appropriate treatment and reduce complications. HIV infection has become a chronic disease and its treatment includes addressing common comorbidities in clinical practice such as arterial bypertension, diabetes and dyslipidemia, in addition to cardiac risk assessment, cancer prevention and guidance on immunization. Initiation of treatment for all HIV patients, regardless of clinical or immunological criteria, adopted by the Ministry of Health since 2013, has now been simplified with more tolerable first-line medications and with fewer drug interactions, which makes its management easy to implement, including by Primary Health Care.

Keywords: Clinical Protocols; HIV; Acquired Immunodeficiency Syndrome; Drug Therapy; Comorbidity.

\section{Resumen}

La infección por VIH es uno de los capítulos del "Protocolo Clínico y Directrices Terapéuticas para la Atención Integral a las Personas con Infecciones de Transmisión Sexual", publicado por el Ministerio de Salud de Brasil en 2020. Es importante que los profesionales de la saludy gestores conozcan los signos y sintomas de la infección por VIH y sepan diagnosticarla, para proporcionar un tratamiento adecuado y reducir complicaciones. La infección por VIH se ba convertido en una enfermedad crónica y su tratamiento incluye abordar comorbilidades comunes en la práctica clínica, como bipertensión arterial, diabetes y dislipidemia, además de la evaluación del riesgo cardiaco, prevención del cáncer y pautas de inmunización. El inicio del tratamiento de VIH, independientemente de criterios clínicos o inmunológicos, adoptado por el Ministerio de Salud en 2013, fue abora simplificado con medicamentos de primera línea más tolerables y con menos interacciones medicamentosas, lo que facilita la implementación de su manejo, incluso en la atención primaria.

Palabras clave: Protocolos Clínicos; VIH; Sindrome de Inmunodeficiencia Adquirida; Tratamiento Farmacológico; Comorbilidad. 


\section{Errata}

No artigo "Protocolo Brasileiro para Infecções Sexualmente Transmissíveis 2020: infecção pelo HIV em adolescentes e adultos", doi: 10.1590/\$1679-4974202100013.esp1, Figura 3 - Testes diagnósticos para detecção da infecção pelo HIV e Figura 4 - Exames complementares iniciais e de seguimento clínico de pessoas com HIV, publicado no periódico Epidemiologia e Serviços de Saúde, v. 30(Esp.1):1-13, nas páginas 5 e 6 :

Figura 3 - Testes diagnósticos para detecção da infecção pelo HIV

Onde se lia:

\begin{tabular}{|l|l|l|}
\hline Primeiro teste & Segundo teste & Diagnóstico \\
\hline ELISA quarta geração $(+)$ & Carga viral HIV $\left(P C R^{b}\right)(+)$ & Infecção pelo HIV \\
\hline ELISA terceira geração $(+)$ & Carga viral HIV $(P C R)(+)$ & Infecção pelo HIV \\
\hline ELISA terceira geração $(+)$ & WesternBlot HIV $(+)$ & Infecção pelo HIV \\
\hline $\operatorname{TR}^{c} 1(+)+\operatorname{TR}^{c} 2(+)$ & Carga viral $(\mathrm{PCR})(+)$ & Infecção pelo HIV \\
\hline
\end{tabular}

Leia-se:

\begin{tabular}{|l|l|l|}
\hline Primeiro teste & Segundo teste & Diagnóstico \\
\hline ELISA quarta geração $(+)$ & Carga viral HIV $\left(P C R^{b}\right)(+)$ & Infecção pelo HIV \\
\hline ELISA $A^{a}$ terceira geração $(+)$ & Carga viral HIV $\left(P R^{b}\right)(+)$ & Infecção pelo HIV \\
\hline ELISAa terceira geração $(+)$ & WesternBlot HIV $(+)$ & Infeç̧ão pelo HIV \\
\hline $\operatorname{TR}^{c} 1(+)+\operatorname{TR}^{c} 2(+)$ & Carga viral $\left(P\left(R^{b}\right)(+)\right.$ & Infecção pelo HIV \\
\hline
\end{tabular}

Figura 4 - Exames complementares iniciais e de seguimento clínico de pessoas com HIV

Onde se lia:

\begin{tabular}{|c|c|c|c|}
\hline Exame & Pré-TARVa & Seguimento & Observação \\
\hline Hemograma completo & Sim & 6-12 meses & Repetir em 2-8 semanas se início ou troca de TARV com AZTb. \\
\hline Creatinina sérica e TFGe & Sim & Anual & $\begin{array}{l}\text { Intervalo de 3-6 meses se uso de TDFd ou outras drogas nefrotóxicas, } \\
\text { TFGe }<60 \mathrm{ml} / \mathrm{min} \text { ou risco aumentado para doença renal (ex.: } \\
\text { diabetes, hipertensão). }\end{array}$ \\
\hline Exame básico de urina & Sim & Anual & $\begin{array}{l}\text { Intervalo de 3-6 meses se uso de TDF ou outras drogas nefrotóxicas, } \\
\text { TFGe }<60 \mathrm{ml} / \mathrm{min} \text {, proteinúria ou risco aumentado para doença renal } \\
\text { (ex.: diabetes, hipertensão). }\end{array}$ \\
\hline AST $^{e}, \mathrm{ALT}^{\dagger}, \mathrm{FAg}, \mathrm{BT} \mathrm{T}^{\mathrm{h}}$ e frações & Sim & Anual & $\begin{array}{l}\text { Intervalos mais frequentes em caso de uso de drogas hepatotóxicas, } \\
\text { doença hepática ou coinfecções com HCV' ou HBVi. }\end{array}$ \\
\hline$C T^{k}, L_{L} L^{\prime}, H D L^{m}$ e TGL ${ }^{n}$ & Sim & Anual & Intervalo de 6 meses se alterado na última análise. \\
\hline Glicemia de jejum & Sim & Anual & $\begin{array}{l}\text { Considerar teste de tolerância à glicose caso o resultado da glicemia } \\
\text { de jejum esteja entre } 100 \text { e } 125 \mathrm{mg} / \mathrm{dL} \text {. }\end{array}$ \\
\hline
\end{tabular}


Continuação

\begin{tabular}{|c|c|c|c|}
\hline Exame & Pré-TARV ${ }^{a}$ & Seguimento & Observação \\
\hline \multirow[t]{2}{*}{$\mathrm{PT} / \mathrm{PPD}^{\circ}$} & \multirow[t]{2}{*}{ Sim } & \multirow{2}{*}{$\begin{array}{l}\text { Anual se LTp-CD4+ } \\
\geq 350 \text { céls } / \mathrm{mm}^{3}\end{array}$} & $\begin{array}{l}\text { Se LT-CD4+<350 céls } / \mathrm{mm}^{3} \text { e excluída tuberculose (TB) ativa, } \\
\text { iniciar tratamento para infecção latente (ILTB) sem necessidade de } \\
\text { realização de PPD. }\end{array}$ \\
\hline & & & $\begin{array}{l}\text { Se tratamento prévio para TB ou ILTB, não há indicação de repetição } \\
\text { - RX de tórax recomendado na consulta pré-TARV. }\end{array}$ \\
\hline Teste imunológico para sífilis & Sim & $\begin{array}{l}\text { Semestral/conforme } \\
\text { indicação }\end{array}$ & Considerar maior frequência de triagem se risco ou exposição. \\
\hline Anti-HCV & Sim & $\begin{array}{l}\text { Anual/conforme } \\
\text { indicação }\end{array}$ & $\begin{array}{l}\text { Considerar maior frequência de triagem se risco ou exposição. } \\
\text { Solicitar carga viral de HCV se anti-HCV positivo ou suspeita de } \\
\text { infecção aguda. }\end{array}$ \\
\hline \multirow{3}{*}{$\begin{array}{l}\text { Triagem HBV }\left(\mathrm{HBsAg}^{q} \text {, antiHBs', }\right. \\
\text { anti-HBc totals) }\end{array}$} & \multirow{3}{*}{ Sim } & \multirow{3}{*}{$\begin{array}{l}\text { Anual/conforme } \\
\text { indicação }\end{array}$} & Considerar maior frequência de triagem se risco ou exposição. \\
\hline & & & Vacinar pessoas não imunizadas. \\
\hline & & & $\begin{array}{l}\text { Pessoas imunizadas (anti-HBS positivo) não necessitam nova triagem } \\
\text { para HBV. }\end{array}$ \\
\hline $\begin{array}{l}\text { IgG para toxoplasmose, sorologia para } \\
\text { HTLV1 } 1^{t} \text { e Chagas }\end{array}$ & Sim & - & $\begin{array}{l}\text { Recomendado lgG toxoplasmose em todos. Sorologia para HTLV-1 e } \\
\text { Chagas em áreas endêmicas. }\end{array}$ \\
\hline Rastreamento das alterações ósseas & Não & $2-3$ anos & $\begin{array}{l}>40 \text { anos ou fatores de risco. Avaliar pela "Ferramenta de avaliação } \\
\text { de risco de fratura" - FRAX Brasil." }\end{array}$ \\
\hline $\begin{array}{l}\text { Avaliação cardiovascular (escala de } \\
\text { risco de Framingham) }\end{array}$ & Sim & Anual & Frequências maiores conforme risco inicial e TARV em uso. \\
\hline Rastreamento de neoplasias & - & - & Abordar no diagnóstico e conforme indicação específica. \\
\hline Imunizações & - & - & Abordar no diagnóstico e conforme indicação específica. \\
\hline Contagem LT-CD4/CD8 & Sim & $6 / 6$ meses & $\begin{array}{l}\text { Com CV-HIV indetectável em } 2 \text { exames e LT-CD4 } \geq 350 \text {, não há } \\
\text { necessidade de monitorar. }\end{array}$ \\
\hline Carga viral HIV & Sim & $\begin{array}{l}\text { 4-8 semanas após início } \\
\text { ou troca e } 6 / 6 \text { meses }\end{array}$ & Repetir se falha virológica. \\
\hline Genotipagem HIV & - & - & $\begin{array}{l}\text { Indicada para gestantes, crianças e adolescentes, casos de HIV-TB, } \\
\text { pessoas infectadas por parceiros em uso de TARV e falha virológica } \\
\text { confirmada. }\end{array}$ \\
\hline
\end{tabular}

Fonte: adaptado do Protocolo Clínico e Diretrizes Terapêuticas para manejo da infecção pelo HIV em adultos, 2018.22

Notas: a) TARV: terapia antirretroviral; b) AZT: zidovudina; c) TFGe: taxa de filtração glomerular estimada; d) TDF: tenofovir; e) AST: aspartatoaminotransferase; f) ALT: alanina aminotransferase; g) FA: fosfatase alcalina; h)BT: bilirrubina total; i) H(V: vírus da hepatite $($; j) HBV: vírus da hepatite B; k)CT: colesterol total; I) LDL: low density lipoprotein; m) HDL: high density lipoprotein; n) TGL: triglicerídeos; 0) PT/PPD: teste tuberculínico; p) LT: linfócitos T; q) HBsAg: antígeno de superfície da hepatite B; r) Anti-HBs: anticorpos contra antígeno de superfície da hepatite B; s) Anti-HBc total: anticorpos totais contra 0 antígeno do núcleo da hepatite B; t) HTLV: vírus T-linfotrópico humano; u) Acessível pelo link: https://www.sheffield.ac.uk/FRAX/tool.aspx?country=55. Ao usar a calculadora FRAX, deve-se clicar na caixa de causa secundária de osteoporose (campo"10. Osteoporose secundária").

Leia-se:

\begin{tabular}{|c|c|c|c|}
\hline Exame & Pré-TARV & Seguimento & Observação \\
\hline Hemograma completo & Sim & $6-12$ meses & Repetir em 2-8 semanas se início ou troca de TARV ${ }^{\mathrm{a}}$ com AZT \\
\hline Creatinina sérica e TFGec & Sim & Anual & $\begin{array}{l}\text { Intervalo de } 3-6 \text { meses se uso de TDF }{ }^{d} \text { ou outras drogas nefrotóxicas, } \\
\text { TFGe }^{\circ}<60 \mathrm{ml} / \text { min ou risco aumentado para doença renal (ex.: } \\
\text { diabetes, hipertensão). }\end{array}$ \\
\hline Exame básico de urina & Sim & Anual & $\begin{array}{l}\text { Intervalo de } 3-6 \text { meses se uso de TDFd ou outras drogas nefrotóxicas, } \\
\text { TFGe'<60ml/min, proteinúria ou risco aumentado para doença renal } \\
\text { (ex.: diabetes, hipertensão). }\end{array}$ \\
\hline AST ${ }^{e}, \mathrm{ALT}^{f}, \mathrm{FA}^{g}, \mathrm{BT}^{\mathrm{h}}$ e frações & Sim & Anual & $\begin{array}{l}\text { Intervalos mais frequentes em caso de uso de drogas hepatotóxicas, } \\
\text { doença hepática ou coinfecções com HCVi ou HBVi. }\end{array}$ \\
\hline
\end{tabular}


Continuação

\begin{tabular}{|c|c|c|c|}
\hline Exame & Pré-TARV ${ }^{a}$ & Seguimento & Observação \\
\hline $\mathrm{CT}^{\mathrm{k}}, \mathrm{LDL} \mathrm{L}^{\prime}, H D L^{\mathrm{m}}$ e $\mathrm{TGL} \mathrm{n}^{\mathrm{n}}$ & Sim & Anual & Intervalo de 6 meses se alterado na última análise. \\
\hline Glicemia de jejum & Sim & Anual & $\begin{array}{l}\text { Considerar teste de tolerância à glicose caso o resultado da glicemia } \\
\text { de jejum esteja entre } 100 \text { e } 125 \mathrm{mg} / \mathrm{dL} \text {. }\end{array}$ \\
\hline $\mathrm{PT} / \mathrm{PPD}^{\circ}$ & Sim & $\begin{array}{l}\text { Anual se } \mathrm{LT}^{\mathrm{P}}-\mathrm{CD} 4+ \\
\geq 350 \text { céls } / \mathrm{mm}^{3}\end{array}$ & 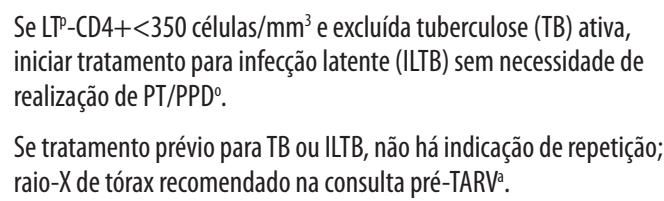 \\
\hline Teste imunológico para sífilis & Sim & $\begin{array}{l}\text { Semestral/conforme } \\
\text { indicação }\end{array}$ & Considerar maior frequência de triagem se risco ou exposição. \\
\hline Anti-HCVi & Sim & $\begin{array}{l}\text { Anual/conforme } \\
\text { indicação }\end{array}$ & $\begin{array}{l}\text { Considerar maior frequência de triagem se risco ou exposição. } \\
\text { Solicitar carga viral de HCV' se anti-HCV' positivo ou suspeita de } \\
\text { infecção aguda. }\end{array}$ \\
\hline $\begin{array}{l}\text { Triagem HBVj (HBsAg }{ }^{q} \text {, antiHBsr, } \\
\text { anti-HBc totals) }\end{array}$ & Sim & $\begin{array}{l}\text { Anual/conforme } \\
\text { indicação }\end{array}$ & $\begin{array}{l}\text { Considerar maior frequência de triagem se risco ou exposição. } \\
\text { Vacinar pessoas não imunizadas. } \\
\text { Pessoas imunizadas (anti-HBS' positivo) não necessitam nova } \\
\text { triagem para HBV. }\end{array}$ \\
\hline $\begin{array}{l}\text { IgG para toxoplasmose, sorologia para } \\
\text { HTLV1 } 1^{t} \text { e Chagas }\end{array}$ & Sim & - & $\begin{array}{l}\text { Recomendado IgG toxoplasmose em todos. Sorologia para HTLV- } 1^{\mathrm{t}} \mathrm{e} \\
\text { Chagas em áreas endêmicas. }\end{array}$ \\
\hline Rastreamento das alterações ósseas & Não & $2-3$ anos & $\begin{array}{l}>40 \text { anos ou fatores de risco. Avaliar pela "Ferramenta de avaliação } \\
\text { de risco de fratura" - FRAX Brasil". }\end{array}$ \\
\hline $\begin{array}{l}\text { Avaliação cardiovascular (escala de } \\
\text { risco de Framingham) }\end{array}$ & Sim & Anual & Frequências maiores conforme risco inicial e TARVa em uso. \\
\hline Rastreamento de neoplasias & - & - & Abordar no diagnóstico e conforme indicação específica. \\
\hline Imunizações & - & - & Abordar no diagnóstico e conforme indicação específica. \\
\hline Contagem LTP-CD4+/CD8+ & Sim & $6 / 6$ meses & $\begin{array}{l}\text { Com carga viral de HIV (CV-HIV) indetectável em } 2 \text { exames e } \\
\text { LTP-CD4+ } \geq 350 \text {, não há necessidade de monitorar. }\end{array}$ \\
\hline Carga viral de HIV & Sim & $\begin{array}{l}\text { 4-8 semanas após início } \\
\text { ou troca e } 6 / 6 \text { meses }\end{array}$ & Repetir se falha virológica. \\
\hline Genotipagem de HIV & - & - & $\begin{array}{l}\text { Indicada para gestantes, crianças e adolescentes, casos de HIV- } \\
\text { tuberculose (HIV-TB), pessoas infectadas por parceiros em uso de } \\
\text { TARVª e falha virológica confirmada. }\end{array}$ \\
\hline
\end{tabular}

Fonte: adaptado do Protocolo Clínico e Diretrizes Terapêuticas para manejo da infecção pelo HIV em adultos, $2018^{22}$

Notas: a) TARV: terapia antirretroviral; b) AZT: zidovudina; c) TFGe: taxa de filtração glomerular estimada; d) TDF: tenofovir; e) AST: aspartato aminotransferase; f) ALT: alanina aminotransferase; g) FA: fosfatase alcalina; h) BT: bilirrubina total; i) H(V: vírus da hepatite (; j) HBV: vírus da hepatite B; k) CT: colesterol total; I) LDL: low density lipoprotein; m) HDL: high density lipoprotein; n) TGL: triglicerídeos; 0) PT/PPD: teste tuberculínico; p) LT: linfócitos T; q) HBsAg: antígeno de superfície da hepatite B; r) Anti-HBs: anticorpos contra antígeno de superfície da hepatite B; s) Anti-HBc total: anticorpos totais contra 0 antígeno do núcleo da hepatite $B$; $\mathrm{t}$ ) HTLV: vírus T-linfotrópico humano; u) Acessível pelo link: https://www.sheffield.ac.uk/FRAX/tool.aspx?country=55. Ao usar a calculadora FRAX, deve-se clicar na caixa de causa secundária de osteoporose (campo"10. 0steoporose secundária"). 